Article Orginal

\title{
Prevalence of Human Papillomavirus Genotypes in Patients with Genital Warts in Gorgan, Iran
}

\author{
Majid Mehri ${ }^{1}$, Saied Hosseinzadeh Kakroudi ${ }^{1}$, Fatemeh Sana Askari ${ }^{2}$, Alireza Mohebbi ${ }^{2}$, \\ Alijan Tabarraei*2,3
}

1. Department of Internal Medicine, School of Medicine, Golestan University of Medical Sciences, Gorgan, Iran

2. Department of Microbiology, School of Medicine, Golestan University of Medical Sciences, Gorgan, Iran

3. Infectious Disease Research Center, Golestan University of Medical Sciences, Gorgan, Iran

* Correspondence: Alijan Tabarraei, Department of Microbiology, School of Medicine, Golestan University of Medical Sciences, Gorgan, Iran

Tel: +989112733321

Email: Tabarraei@goums.ac.ir

Received June 27, $2020 \quad$ Accepted August 18, 2020

\begin{abstract}
Background and objectives: Low-risk and high-risk human papillomavirus (HPV) genotypes are the main cause of anogenital warts. The present study aimed to determine prevalence of HPV genotypes in patients with anogenital warts in Gorgan, northeast of Iran.

Methods: In this cross-sectional study, 40 biopsy samples were taken from patients with anogenital warts in Gorgan, Iran. After DNA extraction, multiplex polymerase chain reaction was carried out for detecting HPV genotypes 54, 18, 16 and 6. Demographic characteristics of subjects including gender, age, education level, marital status, smoking and method of contraception were also collected. Data were analyzed in SPSS 16 software at statistical significance of 0.05 .

Results: The mean age of male and female patients was $31.81 \pm 6.9$ and $27.95 \pm 6.92$ years, respectively. The frequency of HPV-6, HPV-16 and HPV-54 was 77\%, $15 \%$ and $7.5 \%$, respectively. In addition, HPV-18 was not detected in the collected specimens. Co-infection of HPV-54 with HPV-6 and HPV-16 was also observed in some cases. No significant association was found between HPV infection and age, gender, smocking, contraceptive method and education level.

Conclusions: Similar to previous studies in Iran and other countries, HPV type 6 is the predominant cause of genital warts in Gorgan, Iran. Further studies with a larger study population are needed to explore the role of other contributors to HPV-induced genital warts.

Keywords: Genital wart; Condylomata acuminata; Human Papillomavirus
\end{abstract}

DOI: 10.29252/Jcbr.4.3.4 


\section{INTRODUCTION}

Human Papillomavirus (HPV) is the leading cause of cervical cancer, the fourth most common cancer among women worldwide (1).

It is also involved in progression of anogenital tumors and warts. The virus also has an established role in the etiology of oropharyngeal cancers (2). Until now, more than 200 HPV genotypes have been identified, while only one fifth of them are associated with anogenital infections. Genital HPV genotypes are divided into high-risk and low-risk groups based on the carcinogenicity potential $(3,4)$. The high-risk HPV genotypes include 16, 18, 31, 33, 35, $39,45,51,52,56,58,59,68,73$ and 82 , while, HPV types $6,-11,40,42,43,44,54$, $61,70,72,81,89$ are considered low- risk genotypes (5-7). HPV-16, -18 and -51 are the predominant oncogenic genotypes involved in the development of the majority of cervical cancer cases $(8,9)$. Almost $4.5 \%$ of all cases of head and neck cancer as well as anogential cancers are caused by HPV (10). Moreover, high-risk HPV types 16 and 18 are the predominant genotypes in Iran with frequency of $77.5 \%$ and $32.4 \%$ in cervical cancer and head and neck cancer cases, respectively (11). Low-risk HPV types are commonly associated with benign anogenital warts (12). Although most genital warts arise from infections caused by HPV types 6 or 11, high-risk genotypes have been also isolated from patients with genital warts $(13,14)$. Alongside HPV-11 and -6 genotypes, HPV-54 is also isolated from clinical samples of anogenital warts $(15,16)$. Incidence of HPV genotypes (77.5\%) in Iran is almost identical to other parts of the world (11). Low-risk HPV genotypes, including types 6,11 and 54 are more prevalent among Iranian men (17). A similar distribution of HPV genotypes 18, 16, 11 and 6 exists among Iranian women $(18,19)$.

Therapeutic approaches for the treatment of genital warts include podophyllin, trichloroacetic acid, cryotherapy, electrocautery, imiquimod, carbon dioxide laser and surgery. Despite treatment, recurrence rate of genital warts ranges between $40 \%$ and $90 \%$ (13). In this study, we investigate the frequency of HPV infection in patients with genital warts in Gorgan, North of Iran.

\section{MATERIALS AND METHODS}

Patient recruitment and sample collection From February 2018 to July 2018, this cross-sectional study was carried out on anogenital wart samples. The study was approved (approval code of IR.GOUMS.REC.1396.120) by the Ethical Committee of the Golestan University of Medical Sciences, Gorgan, Iran. A written informed consent was obtained from all subjects. The samples were collected from 40 patients (21 men and 29 women) with mean age of $29.98 \pm 7.084$ years (age range: 18 to 48 years) who voluntarily participated in the study. Initial diagnosis of genital warts was made by a dermatologist. One representative biopsy sample was collected from each patient. Demographic characteristics including marital status, smocking, contraceptive method, educational level and medical history were collected.

\section{DNA extraction and HPV genotyping}

A Genomic DNA extraction kit MachereyNagel, Germany) was used For DNA extraction from sections of anogenital arts.A multiplex polymerase chain reaction (PCR) experiment was designed to investigate presence of low-risk (types 6 and 54) and high- risk (types 16 and 18 ) HPV genotypes. HPV types 16 and 18 are the predominant high-risk genotypes in Iran, while HPV-6 is the most common low-risk HPV genotype in anogenital specimens. However, the prevalence of the low-risk HPV genotype 54 is not clear. Four primer pairs encompassing the HPV L1 coding sequence were designed (Table 1). PCR was performed as follows: initial denaturation at 
$94{ }^{\circ} \mathrm{C}$ for 5 minutes, followed by 35 cycles at $94{ }^{\circ} \mathrm{C}$ for 30 seconds, at $58{ }^{\circ} \mathrm{C}$ for 30 seconds and at $72{ }^{\circ} \mathrm{C}$ for 40 seconds. PCR products were electrophoresed on $1 \%$ garose gel. A HPV-positive specimen and a specimen- free sample were used as the positive and negative controls, respectively.

\section{Statistical analysis}

Descriptive analysis was performed using SPSS 16.0 software package. Crosstabulation and Chi-square test were performed to evaluate association of HPV infection with the demographical factors. Results are reported as frequency percentage among patients with HPVpositive genital warts. A p-value of less than 0.05 was considered statistically significant.

\section{RESULTS}

The mean age of men and women was $31.81 \pm 6.9$ and $27.95 \pm 6.92$ years, respectively. The frequency of HPV genotypes among patients with HPVpositive genital warts is shown in table 2 . The highest and lowest genotype frequency was related to HPV-6 (77.5\%) and HPV-54 (7.5\%), respectively. In addition, HPV-18 was not detected in any of the samples. Coinfection with two or three HPV genotypes was also observed. Accordingly, coinfection of HPV-6 with HPV-54 and HPV16 with HPV-54 was detected in two patients. In addition, a co-infection of HPV6, HPV-16 and HPV-54 was observed in one married woman. As shown in table 2, HPV-6 was more prevalent in men than in women $(\mathrm{P}>0.05)$. On the contrary, HPV-16 was only detected among women. The prevalence of HPV-16 was $60.7 \%$ among patients aged 20 to 30 years. Overall, 29 patients were married and 13 patients were cigarette smokers. Of 40 patients, five had primary education, 15 had high school diploma, 18 had bachelor's degree and four had post-graduate education. Two patients had hypertension and high blood low- density lipoprotein level. Condom use $(n=38)$ was the preferred contraceptive method, followed by tubectomy $(\mathrm{n}=1)$ and contraceptive pills $(n=1)$. There was no significant relationship between HPV infection and demographic characteristics.

\section{DISCUSSION}

Genital warts are benign epithelial cell growths caused by sexually transmitted HPV infection $(21,22)$. Genotyping of genital HPV is of great clinical significance in terms of developing treatment plans as well as follow-up and prevention strategies (23). Low-risk HPVs are frequency associated with anogenital warts or condylomata acuminata. Based on test sensitivity, HPV-6 can be detected in more than $90 \%$ of clinical samples of genital warts (24). In this study, $77.5 \%$ of HPVpositive samples were infected with HPV-6. In a previous study on 100 tissue specimens from women with HPV genital warts in Iran, HPV types 6 and 11 were found in $49 \%$ and $67 \%$ of patients, respectively. The mentioned study also found no significant association between marriage and HPV-11 (14). These reports demonstrate the high prevalence of low risk HPV types 6 and 11 in anogenital warts. In recent reports, 20$50 \%$ of patients with genital warts harbored high-risk HPV genotypes. However, we found no HPV-18 and seven (15\%) HPV16-positive samples among patients with anogenital warts. Following low- risk HPV types 6 and 11, HPV-16 is reported to be the most frequent HPV type isolated from anogenital warts. Consistent with our results, Ma et al. found HPV-16 in $10.6 \%$ of patients with genital warts (25). Similar to our results, Jalilian et al. found a high frequency of HPV-6 (64.8\%) and HPV-16 (9.2\%) in patients with genital warts in West of Iran (18). In the present study, coinfection with HPV types 6, 16 and 54 was observed in some cases. Another study also reported a high rate of HPV-6 and -11 co- 
infection in genital warts (17). HPV-54 is mainly isolated from genital tumors (26). Similarly, the prevalence of HPV-18 is not high in anogenital warts. In this regard, Ozaydin-Yavuz et al. detected one $(1.5 \%)$ case of HPV-18 infection among 66 patients with genital warts (13).Furthermore, Park et al. observed co-infection with HPV18 in three cases (27). This could be due to the fact that HPV-18 poses a greater risk for development of glandular lesions rather than squamous lesions (28). Several contributing risk factors have been suggested for anogenital HPV infections.

Based on our results, young adults (20-30 years old) were at a higher risk of HPV infection. Boda et al. also reported a higher incidence rate for high-risk HPV infection in patients under 35 years of age (29). According to Sohrabi et al., the frequency of HPV genotypes in cervical legions and genital warts was higher among patients aged 30-39 years (20). In a study by Chen et al., a large proportion of low-risk HPV genotypes was detected in patients under 20 years of age (30).

We found no association between HPV infection and gender, smocking, condom use or education level. Further studies with a larger study population could help clarify the role of environmental factors in the incidence of HPV infection. In the present study, HPV-6 was more prevalent in men than in women. In a study on 66 patients with anogenital warts, Ozaydin-Yavuz et al. found a relationship between HPV type distribution and age, gender, place of residence and number of sexual partners. Similar to our findings, they detected a higher frequency of HPV genotypes in men with genital warts (13). Another study in Iran also reported a higher frequency of HPV-6 in HPV-positive genital specimen from men (17).

However, geographical factors can affect the distributions of HPV infection in men and women.

\section{CONCLUSION}

Based on the results, HPV-6 is the predominant cause of anogenital warts in Gorgan, northeastern Iran. In addition, the rate of HPV infection was slightly higher in patients under 30 years of age. Further studies with a larger study population are needed to explore the role of other contributors to HPV-induced genital warts. induced genital warts.

\section{ACKNOWLEDGMENTS}

The Department of Microbiology of Golestan University of Medical Science is acknowledged for their support in conducting this study.

\section{DECLARATIONS}

Funding

Not applicable.

Ethics approvals and consent to participate The study was approved (approval code of IR.GOUMS.REC.1396.120) by the Ethical Committee of the Golestan University of Medical Sciences, Gorgan, Iran. A written informed consent was obtained from all subjects

\section{Conflict of interest}

The author declares that there is no conflict of interest regarding publication of this article.

\section{REFERENCES}

1. Unger ER, Ruffin MT, Diaz-Arrastia C.Human papillomaviruses. In: Clinical Gynecology, Second Edition. 2015.p.37181.

2. Kofoed K, Sand C, Forslund ,MadsenK. Prevalence of human papillomavirus in anal and oral sites among patients with genital warts. Acta Derm Venereol. 014;94(2):207https://doi.org/10.2340/00015555-1718 11. 
3. Yuanyue L, Baloch Z, Yasmeen N,TaoY,Xiaomei W, Xueshan X. The distribution ofhuman papillomavirus genotypes in cervicalcancer and intraepithelial neoplasia lesionsamong Chinese women in Yunnan Province. JInfec Public Health. 2018;11(1):105-10.

4. Camara HB, Anyanwu M, Wright E,Kimmitt PT. Human papilloma virus genotype distribution and risk factor analysis amongst reproductive-age women in urban Gambia. J Med Microbiol. 2018;67(11):1645-

4.https://doi.org/10.1099/jmm.0.000848

5. Muñoz N, Bosch FX, De Sanjosé S, Herrero R, Castellsagué X, Shah K V., et al. Epidemiologic classification of human

papillomavirus types associated with cervical cancer. $N$ Engl J Med. 2003;348(6):518-27.

https://doi.org/10.1056/NEJMoa021641

6. Lin CY, Chen HC, Lin RW, You SL, You CM, Chuang LC, et al. Quality assurance of genotyping array for detection and typing of human papillomavirus. $\mathbf{J}$ Virol Methods. 2007;140(1-2):1-9. https://doi.org/10.1016/j.jviromet.2006.10.0 $\underline{04}$

7. Zuna RE, Allen RA, Moore WE, Lu Y, Mattu R, Dunn ST. Distribution of HPV genotypes in 282 women with cervical lesions: Evidence for three categories of intraepithelial lesions based on morphology and HPV type. Mod Pathol. 2007;20(2):167-74.

https://doi.org/10.1038/modpathol.3800723

8. Piana A, Sotgiu G, Castiglia P, Pischedda S,Cocuzza C, Capobianco G, Marras V, DessoleS, Muresu E. Prevalence and type distributionof human papillomavirus infection in womenfrom North Sardinia, Italy. BMC PublicHealth. 2011 Dec 1;11(1):785. https://doi.org/10.1186/1471-2458-11-785

9. Halfon P, Ravet S, Khiri H, Penaranda G, Lefoll C. Incident HPV 51 infection after prophylactic quadrivalent human papillomavirus (types 6, 11, 16, and 18)L1virus like particle vaccine Gardasil/silgard®.Clin Med Insights Case Reports. 2010;3:6971.https://doi.org/10.4137/CCRep.S508

10. de Martel C, Plummer M, Vignat J, Franceschi S. Worldwide burden of cancer attributable to HPV by site, country and HPV type. International journal of cancer. 2017 Aug 15;141(4):664-70. https://doi.org/10.1002/ijc.30716

11. Jalilvand S, Shoja Z, Hamkar R. Human papillomavirus burden in different cancers in Iran: a systematic assessment. Asian Pac J Cancer Prev. 2014 Jan 1;15(17):7029-35.

https://doi.org/10.7314/APJCP.2014.15.17. 7029

12. Ebrahimi A, Moradi MR, Rezaei M, Kavoussi H, Madani SH, Mohammadamini $\mathrm{K}$, et al. Comparison of the risk factors and HPV types in males with anogenital warts with and without involvement of the urethral meatus in Western Iran. Acta Dermatovenerologica Alpina, Pannonica Adriat. 2017;26(3):55-8

https://doi.org/10.15570/actaapa.2017.24

\section{Ozaydin-Yavuz G, Bilgili SG,}

Guducuoglu H, Yavuz IH, Elibuyuk-Aksac S, Karadag AS. Determinants of high-risk human papillomavirus infection in anogenital warts. Postep Dermatologii i Alergol. 2019;36(1):76-

81. 
https://doi.org/10.5114/ada.2019.82915

14. Jamshidi M, Shekari M, Nejatizadeh AA, Malekzadeh K, Baghershiroodi M, Davudian P, et al. The impact of human papillomavirus (HPV) types 6, 11 in women with genital warts. Arch Gynecol Obstet.

2012;286(5):1261-7.

15. Dareng EO, Adebamowo SN, Famooto A, Olawande O, Odutola MK, Olaniyan Y, et al. Prevalence and incidence of genital warts and cervical Human Papillomavirus infections in Nigerian women 11 Medical and Health Sciences 1117 Public Health and Health Services. BMC Infect Dis. 2019;19(1):27.

https://doi.org/10.1186/s12879-018-3582-y

16. Salehi-Vaziri M, Sadeghi F, Hashemi FS, Haeri H, Bokharaei-Salim F, Monavari $\mathrm{SH}$, et al. Distribution of human papillomavirus genotypes in Iranian women according to the severity of the cervical lesion. Iran Red Crescent Med J. 2016;18(4).

https://doi.org/10.5812/ircmj.24458

17. Salehi-Vaziri M, Sadeghi F, Bokharaei- Salim F, Younesi S, Alinaghi S, Monavari $\mathrm{SH}$, et al. The prevalence and genotype distribution of human

papillomavirus in the genital tract of males in Iran. Jundishapur J Microbiol.

2015;8(12).

18. Jalilian S, Izadi B, Madani SH, Mohajeri $\mathrm{P}$. The prevalence and genotype distribution of human papillomavirus types in the general female population in West of Iran. Jundishapur J Microbiol. 2017;10(3) :e40855.

https://doi.org/10.5812/jim.40855

19. Sohrabi A, Hajia M. Cervical cancer and genital infections: Assessment of performance and validation in human papillomavirus genotyping assays in Iran, its neighbouring countries and Persian gulf area. Iran J Pathol. 2017;12(1):35-44. https://doi.org/10.30699/ijp.2017.24229

20. Sohrabi A, Hajia M, Jamali F, Kharazi F. Is incidence of multiple HPV genotypes rising in genital infections? J Infect Public Health. 2017;10(6):730-3. https://doi.org/10.1016/j.jiph.2016.10.006

21. Comparetto C, Borruto F. Human papillomavirus infection: Overview. In: Handbook on Human Papillomavirus: Prevalence, Detection and Management. 2013.

\section{Lytwyn A, Sellors JW. Sexually}

transmitted human papillomaviruses: Current concepts and control issues. Can J Hum Sex. 1997;6(2):113-26.

23. Franco EL. Persistent HPV infection and cervical cancer risk: Is the scientific rationale for changing the screening paradigm enough? Journal of the National Cancer Institute. 2010;102(19):1451-3. https://doi.org/10.1093/jnci/djq357

24. Gissmann L, De Villiers E -M, Hausen $\mathrm{H}$ Zur. Analysis of human genital warts (condylomata acuminata) and other genital tumors for human papillomavirus type 6 DNA. Int $\mathbf{J}$ Cancer. 1982;29(2):143-6. https://doi.org/10.1002/ijc.2910290205

25. Ma L, Lu S, Jiang Y, Li M, Cong X, Cao Y. Distribution of human papillomavirus genotypes (2014-2016) in women with genital warts at a sexually transmitted disease clinic in Beijing, China. Future Virol. 2018;13(2):111 https://doi.org/10.2217/fvl-2017-0097 
26. Favre M, Kremsdorf D, Jablonska S, Obalek S, Pehau-Arnaudet Gér, Croissant $\mathrm{O}$, et al. Two new human papillomavirus types

(HPV54 and 55) characterized from genital tumours illustrate the plurality of genital HPVs. Int J Cancer. 1990;45(1):40-6. https://doi.org/10.1002/ijc.2910450109

\section{Park SJ, Seo J, Ha SH, Jung GW.}

Prevalence and determinants of high-risk human papillomavirus infection in male genital warts. Korean J Urol 2014;55(3):207-12.

https://doi.org/10.4111/kju.2014.55.3.207

28. Robadi IA, Pharaon M, Ducatman BS. The importance of high-risk human papillomavirus types other than 16 and 18 in cervical neoplasia. Arch Pathol Lab Med.

2018;142(6):693-5.

29. Boda D, Neagu M, Constantin C,

Voinescu RN, Caruntu C, Zurac S, et al.
HPV strain distribution in patients witl genital warts in a female population sample Oncol Lett. 2016;12(3):1779-82 https://doi.org/10.3892/ol.2016.4903

30. Chen X, Li L, Lai Y, Liu Q, Yan J. Tang Y.Characteristics of human papillomaviruses infection in men with genital warts in Shanghai. Oncotarget. 2016;7(33):53903-10. https://doi.org/10.18632/oncotarget.9708

31. Luna-Aguirre CM, Reyes-Cortés LM Torres-Grimaldo AA, Karr-De-León SF Cerda-Flores RM, Melo-Nava B, et al.

Prevalence of human papillomavirus types in North and Central regions of Mexico.

Epidemiol Infect. 2018;146(13):1724-30 https://doi.org/10.1017/S0950268818001747

How to Cite: Mehri M, Hosseinzadeh Kakroudi S, Askari F S, Mohebbi A, Tabarraei A. Prevalence of Human Papillomavirus Genotypes in Patients with Genital Warts in Gorgan, Iran. jcbr. 2020; 4 (2

Table1. Sequences of the primers used in the multiplex-PCR experiment

\begin{tabular}{|c|c|c|}
\hline HPV genotypes & Primers (5' to 3') & Size (bp) \\
\hline \multirow{2}{*}{ HPV-54 } & Forward: TTGCATCCACGCAGGATAGC & \multirow{2}{*}{386} \\
\hline & Reverse: ACGTAGGCCAGCCTGTAGTA & \\
\hline \multirow{2}{*}{ HPV-18 } & Forward: CGTGGTCAGCCTTTAGGTGT & \multirow{2}{*}{95} \\
\hline & Reverse: GAAACATTAGACGTGGCGGC & \\
\hline \multirow{2}{*}{ HPV-16 } & Forward: CGTGGTCAGCCATTAGGTGT & \multirow{2}{*}{643} \\
\hline & Reverse: TGCCATTATTGTGGCCCTGT & \\
\hline \multirow{2}{*}{ HPV-6 } & Forward: AAAGTTGTTGCCACGGATGC & \multirow{2}{*}{204} \\
\hline & Reverse: AGACGAGTCAGGCAATGCAA & \\
\hline
\end{tabular}


Table2. Frequency distribution of HPV genotypes among patients with anogenital warts

\begin{tabular}{|l|l|l|l|}
\hline \multirow{2}{*}{$\begin{array}{l}\text { HPV } \\
\text { genotypes }\end{array}$} & $\begin{array}{l}\text { Number } \\
\text { patients }\end{array}$ & Mem of positive & \multirow{2}{*}{ Total } \\
\cline { 2 - 3 } & Female & Male & \\
\hline HPV-54 & $2(10.53 \%)$ & $1(4.76 \%)$ & $3(7.5 \%)$ \\
\hline HPV-18 & $0(0 \%)$ & $0(0 \%)$ & $0(0 \%)$ \\
\hline HPV-16 & $6(31.58 \%)$ & $0(0 \%)$ & $6(15 \%)$ \\
\hline HPV-6 & $11(57.9 \%)$ & $20(95.24 \%)$ & $\begin{array}{l}31 \\
(77.5 \%)\end{array}$ \\
\hline Total $(\%)$ & $19(47.5 \%)$ & $21(52.5 \%)$ & $40(100 \%)$ \\
\hline
\end{tabular}

